\title{
Damage and Fatigue Failure of Conventional and Bulk-Filled Resin Composites
}

\author{
Rana Alkattan ${ }^{1,2}$, Subir Banerji ${ }^{1,3}$, Sanjukta Deb ${ }^{1 *}$ \\ ${ }^{1}$ Centre for Oral, Clinical and Translational Sciences, Faculty of Dentistry, Oral and Craniofacial Sciences, King's College London, \\ London, United Kingdom \\ ${ }^{2}$ Department of Restorative Dental Science, King Saud Bin Abdulaziz University for Health Sciences, Riyadh, Saudi Arabia \\ ${ }^{3}$ Department of Prosthodontics, University of Melbourne, Melbourne, Australia \\ Email: *sanjukta.deb@kcl.ac.uk
}

How to cite this paper: Alkattan, R., Banerji, S. and Deb, S. (2022) Damage and Fatigue Failure of Conventional and Bulk-Filled Resin Composites. Open Journal of Stomatology, 12, 62-76. https://doi.org/10.4236/ojst.2022.122006

Received: October 26, 2021

Accepted: February 21, 2022

Published: February 24, 2022

Copyright (c) 2022 by author(s) and Scientific Research Publishing Inc. This work is licensed under the Creative Commons Attribution International License (CC BY 4.0).

http://creativecommons.org/licenses/by/4.0/ (c) (i) Open Access

\begin{abstract}
Objectives: Resin-based composites are the most widely used dental restorative materials. Bulk-fill resin composites are of rising interest as they can be clinically applied in thicker increments compared to conventional composites. The purpose of the study was to evaluate the flexural fatigue strength of a conventional and bulk-filled resin composite placed incrementally or non-incrementally. Methods: Resin composite specimens were fabricated using either a conventional (Brilliant EverGlow ${ }^{\circledR}$ ) or a bulk-fill (Fill-Up! ${ }^{\mathrm{TM}}$ ) resin composite by either non-incremental filling $\left(2 \times 2 \times 25 \mathrm{~mm}^{3}\right)$ or in increments of $\left(1 \times 2 \times 25 \mathrm{~mm}^{3}\right)$. Specimens were stored in distilled water for 24 $\mathrm{h}$ or thermocycled for 5000 cycles. The static flexural strength $(\sigma)$, flexural fatigue limit (FFL) after $10^{5}$ cycles and post-fatigue flexural strength $(\mathrm{PF} \sigma)$ were measured. Data were analyzed using ANOVA, with a post-hoc Tukey's test to compare mean FFL $(\mathrm{p}<0.05)$. Results: Bulk-filled composites showed higher static $\sigma$ and $\mathrm{PF} \sigma$ compared to conventional composites regardless of incremental cure or thermocycling $(\mathrm{p}<0.05)$. However, the non-incrementally placed conventional composite exhibited superior FFL. Thermocycling caused a significant decrease in $\sigma$ and FFL for conventional composites but not bulk-filled composites. There was no significant difference in $\mathrm{PF} \sigma$ compared to $\sigma$ after $24 \mathrm{~h}$ storage, but a significant increase in $\mathrm{PF} \sigma$ after thermocycling (p $<0.05)$. Conclusions: The type of composite rather than incremental placement had a greater effect on flexural strength, suggesting that operator placement technique had less influence than material selection. Thermocycling in combination with cyclic loading caused a strengthening effect in the composites, likely due to the absorption and dissipation of stresses, thereby enhancing resistance to fracture.
\end{abstract}




\section{Keywords}

Cyclic Fatigue, Flexural Fatigue Limit, Flexural Strength, Bulk-Fill, Resin

Composite, Incremental Layering

\section{Introduction}

Resin-based composites are widely used for dental restorations due to their excellent aesthetics and suitable mechanical properties that can be directly placed using bonding agents, thus conserving sound tooth tissue [1]. Dental resin composites undergo setting via free radical polymerisation that helps clinical operators in effective placement and contouring of restorations prior to setting; however, the conventional composites exhibit a limited depth of cure, hence are applied in small increments to build a restoration. The polymerisation of the methacrylate monomers present in resin composites is inevitably accompanied by shrinkage that is directly or indirectly related to the contraction stresses that develop causing pain, sensitivity and gap formation resulting in microleakage, all of which may lead to secondary caries and ultimate failure of the restoration [2] [3]. Resin Composites may pull away from the cavity margins leading to gap formation especially under cyclic mechanical and thermal stresses experienced in the oral environment resulting in microleakage due to adhesive bond failure [4]. Alternatively, cuspal deflection may occur where bonds hold, but compliant tooth structure is deformed under the applied stress leading to cracks and craze lines, and, ultimately, decreasing the fracture resistance of the cusps [5].

Incremental placement of composites has long been adopted by clinicians to allow adequate curing through the thickness of restorations. An additional benefit of the technique is believed to cause a reduction in the cavity configuration factor (C-factor) [6] [7]; however, this concept is not universally accepted [8]. Cusp deflection reportedly increases with increasing cavity dimension and C-factor; thus, use of an incremental filling technique rather than bulk-filling is recommended to reduce cuspal strain [9]. Nonetheless, an incremental layering technique carries a greater risk of incorporating impurities and/or air bubbles between layers and additionally increases clinical chair time. Incremental curing may also cause deformation of large restorations, ultimately inducing greater cuspal movement than bulk placement [10]. As a direct consequence of the limitations of conventional composites, the introduction of bulk-filled composites no doubt simplified clinical placement, which may essentially decrease cuspal strain and reduce operator errors. Since bulk-filled resin composites can be cured in increments up to $4 \mathrm{~mm}$ deep, it not only decreases the number of layers in larger cavities but has been reported to lower cuspal strain and deformation [11]. This has the advantage of reducing clinical chair time and technique sensitivity, providing an efficient restorative option for a variety of clinical applications. 
Fatigue has hence been recognized as one of the major contributing factors in the survival of resin composites [12]. Internal or external micro flaws, which can arise during fabrication or incorporated during clinical manipulation between composite layers in incremental placement techniques, may contribute to fatigue failure [13]. From a clinical standpoint, it is important to ascertain if eliminating potential voids through bulk-filling of a composite would impact fatigue behaviour. Surprisingly, data related to fatigue behaviour of bulk-fill and incremental resin composite restorations are scarce.

Therefore, the aim of this study was to evaluate the fatigue behaviour of a conventional and bulk-fill resin composite placed using two techniques: non-incrementally or incrementally and evaluate the effects of thermocycling. The null hypotheses were: 1) conventional or bulk-fill composites placed non-incrementally or incrementally will have the same fatigue resistance and 2) thermocycling will be detrimental to fatigue behaviour of resin composites.

\section{Materials and Methods}

\subsection{Specimen Preparation for Flexural and Fatigue Tests}

A conventional resin composite (Brilliant EverGlow ${ }^{\circledR}$ ) and a bulk-fill resin composite (Fill-Up! ${ }^{\mathrm{TM}}$ ) were used in this study (Table 1). Metal moulds with dimensions of $2 \times 2 \times 25 \mathrm{~mm}$ were used by either filling the entire mould at once according to ISO 4049 standard or in increments of $(1 \times 2 \times 25 \mathrm{~mm})$. The composite was cured for $20 \mathrm{~s}$ using an LED unit (Elipar ${ }^{\mathrm{TM}}$ DeepCure-S, 3M ESPE, St. Paul, MN, USA) with an output intensity of $1400 \mathrm{~mW} / \mathrm{cm}^{2}$ at five overlapping points on the upper and lower sides. The specimens were then polished with 1200-grit silicon carbide paper (Struers, Copenhagen, Germany) to remove any flashes and surface scratches and dimensions were confirmed with a digital calliper. The specimens were then stored under one of the following conditions:

- Distilled water at $37^{\circ} \mathrm{C}$ for 24 hours;

- Thermocycled for 5000 cycles in a water bath between $5( \pm 2)^{\circ} \mathrm{C}$ and 55 $( \pm 2)^{\circ} \mathrm{C}$ with a dwell time of 30 seconds in each bath and a transfer time of 10 seconds between baths.

240 specimens were prepared and divided into 8 groups $(n=30): 4$ groups per resin composite type, 4 groups per placement technique, and 4 groups per storage condition. A flowchart of the experimental design is shown in Figure 1.

Table 1. The bulk-filled and conventional resin composite materials used in this study with filler size and fractions.

\begin{tabular}{|c|c|c|c|c|}
\hline $\begin{array}{l}\text { Composite brand } \\
\text { name (lot) }\end{array}$ & Manufacturer & Composite material & Filler size $(\mu \mathrm{m})$ & $\begin{array}{c}\text { Inorganic filler } \\
\text { particles (wt\%/vol\%) }\end{array}$ \\
\hline $\begin{array}{c}\text { Brilliant Everglow }{ }^{\circledR} \\
(107067)\end{array}$ & $\begin{array}{l}\text { Coltène/Whaledent Ltd } \\
\text { (West Sussex, UK) }\end{array}$ & Universal microhybrid composite & $0.02-1.5$ & $74 / 56$ \\
\hline Fill-up! ${ }^{\mathrm{TM}}(105466)$ & $\begin{array}{l}\text { Coltène/Whaledent Ltd } \\
\text { (West Sussex, UK) }\end{array}$ & $\begin{array}{l}\text { Dual-cure bulk-fill microhybrid } \\
\text { composite }\end{array}$ & $0.1-5$ & $65 / 49$ \\
\hline
\end{tabular}




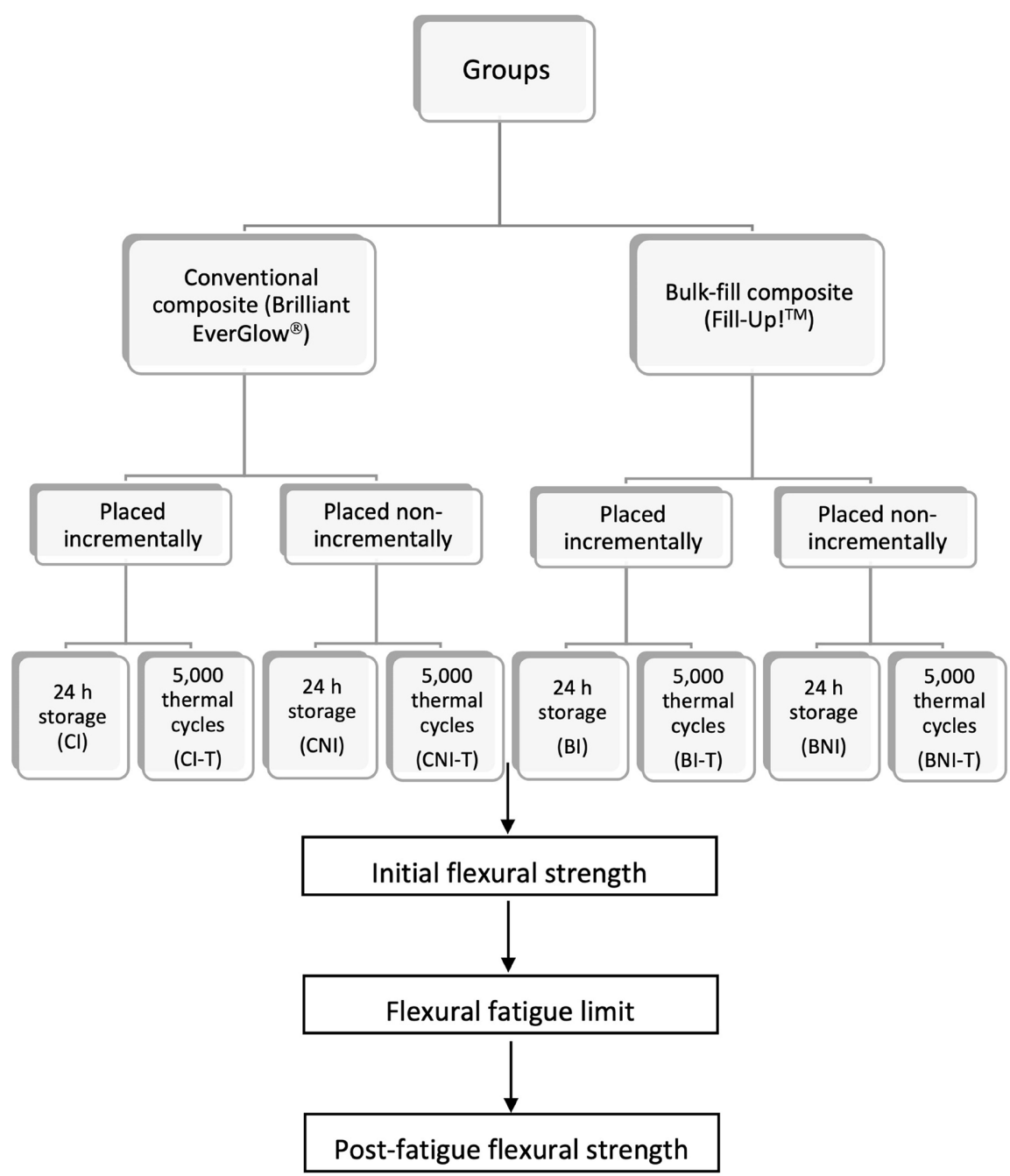

Figure 1. Flowchart of the experimental design for fatigue testing of resin composites.

\subsection{Initial Flexural Strength $(\sigma)$}

A four-point bend test was conducted $(n=5)$ following the ISO 4049 standard to obtain the static flexural strength of the resin composites for determining the parameters for fatigue testing. The $25 \mathrm{~mm}$ specimens were placed between two upper and two lower spherical supports which were distanced at $7 \mathrm{~mm}$ and 20 $\mathrm{mm}$ apart, respectively, with a diameter of $2 \mathrm{~mm}$ each, with the resin composite increment interface perpendicular to the loading axis. Specimens were loaded until fracture at a crosshead speed of $0.75 \mathrm{~mm} / \mathrm{min}$ using a universal testing machine (Instron, model 5569A, High Wycombe, UK). The flexural strength $(\sigma)$ was obtained using the following Equation (1):

$$
\sigma=\frac{P L}{w b^{2}}
$$

where, $P$ is the maximum load exerted on the specimen $(\mathrm{N}), L$ is the distance between the lower supports $(20 \mathrm{~mm}), w$ is the width of the specimen $(2 \mathrm{~mm})$ and $b$ is the height of the specimen $(2 \mathrm{~mm})$. 


\subsection{Flexural Fatigue Limit (FFL)}

The flexural fatigue limit (FFL) was determined over $10^{5}$ cycles using a four-pointbending configuration at a frequency of $1 \mathrm{~Hz}$ (Bose ElectroForce 3330 series II, TA Instruments, New Castle, DE, USA) using the "staircase" approach described by Draughn [14] $(n=25)$. For every cycle, the stress was alternated between 1 $\mathrm{MPa}$ and the maximum stress, with the specimen first being tested at a maximum stress level, approximately $55 \%$ of initial flexural strength, for each of the groups. The maximum applied stress for sequential cycles was then increased or decreased by $5 \mathrm{MPa}$, according to whether the previous test passed or failed.

The mean FFL was determined using Equation (2) and the standard deviation (SD) using Equation (3):

$$
\begin{gathered}
\mathrm{FFL}=X_{0}+d\left(\frac{\sum i n_{i}}{\sum n_{i}} \pm 0.5\right) \\
\mathrm{SD}=1.62 d\left(\frac{\sum n_{i} \sum i^{2} n_{i}-\left(\sum i n_{i}\right)^{2}}{\left(\sum n_{i}\right)^{2}}+0.029\right)
\end{gathered}
$$

where, $X_{0}$ is the lowest stress level considered in the analysis and $d$ is the fixed stress increment $(5 \mathrm{MPa})$. The FFL analysis was based on the least frequent event (pass vs failure); the negative sign being used when analysis was based on failure and the positive sign used otherwise. The lowest stress level considered in the analysis was designated as $i=0$, the next as $i=1$, and so on, and $n_{i}$ is the number of failures that occurred at the given stress levels.

\subsection{Post-Fatigue Flexural Strength (PF $\sigma$ )}

Specimens that survived the FFL testing were subjected to another four-pointbending test to evaluate the post-fatigue flexural strength using the same configuration described in Section 2.2. The mean PF $\sigma$ was then calculated using Equation (1).

\subsection{Fractographic Evaluation}

The fractured resin composite surfaces were viewed under a light stereomicroscope (Wild M3Z, Heerbrugg, Switzerland) at 40× magnification. Representative specimens were then selected for SEM observation. The specimens were placed in an ultrasonic bath with distilled water for 5 min followed by cleaning with ethanol. The two ends of the fractured surfaces were then mounted on aluminium stubs and sputter-coated with gold and viewed using Jeol JCM 6000 Plus (JEOL, Tokyo, Japan).

\subsection{Statistical Analysis}

After analysing the normality of the data using Shapiro-Wilk test, the initial flexural strength of the resin composite samples was analysed using a three-way ANOVA with factors of composite type, storage condition and incremental cure. The flexural fatigue limit and post-fatigue flexural strength of the resin compo- 
site samples were then analysed using one-way ANOVA, with a post-hoc Tukey's test used to identify significant differences among the groups. Tests were carried out with a significance level defined as $\alpha=0.05$. All statistical analysis was performed using GraphPad Prism software 9.0 for MacOS (GraphPad Software Inc., Version 9.0.1, San Diego, California).

\section{Results}

\subsection{Initial Flexural Strength $(\sigma)$}

The mean static flexural strengths $(\sigma)$ of the composites are presented in Table 2. The factors, composite type $(\mathrm{F}=20.68 ; \mathrm{df}=1 ; \mathrm{p}<0.05)$ and storage condition $(\mathrm{F}=46.14 ; \mathrm{df}=1 ; \mathrm{p}<0.05)$ showed statistically significant effects, but the incremental cure as well as the interaction between the three factors (composite type, storage condition and incremental cure) did not exhibit statistically significant differences ( $p>0.05$ ). The flexural strength of the composites cured incrementally or non-incrementally measured at $24 \mathrm{~h}$ showed no statistically significant differences between the groups ( $p>0.05$ ). However, following thermocycling, the conventional non-incremental (CNI-T) group exhibited lower strength than bulk-filled groups BNI-T and BI-T $(\mathrm{p}<0.05)$. Moreover, conventional composites placed both with no increment and incrementally, CNI and CI, showed a significant decrease in flexural strength following thermocycling while bulk-filled composites maintained higher strength values under both storage conditions $(\mathrm{p}<0.05)$.

Table 2. Mean and standard deviation (SD) static flexural strength ( $\sigma$ ), post-fatigue flexural strength $(\mathrm{PF} \sigma)$ and flexural fatigue limits (FFL) of the conventional and bulk fill resin composites cured both incrementally and non-incrementally.

\begin{tabular}{|c|c|c|c|c|c|}
\hline $\begin{array}{c}\text { Storage } \\
\text { condition }\end{array}$ & Group & $\begin{array}{c}\sigma(\mathrm{SD}) \\
\mathrm{MPa}\end{array}$ & $\begin{array}{c}\mathrm{PF} \sigma(\mathrm{SD}) \\
\mathrm{MPa}\end{array}$ & $\begin{array}{l}\text { FFL (SD) } \\
\quad \mathrm{MPa}\end{array}$ & $\begin{array}{c}\text { FFL change } \\
(\%)^{\#}\end{array}$ \\
\hline \multirow{4}{*}{$24 \mathrm{~h}$} & $\mathrm{CNI}$ & $98.8(9.5)^{A}$ & $100.0(18.5)$ & $83.1(31.5)^{\mathrm{a}, \mathrm{A}}$ & -15.9 \\
\hline & $\mathrm{CI}$ & $100.9(13.9)^{\mathrm{A}}$ & $111.8(13.8)$ & $68.9(10.7)^{\mathrm{ab}}$ & -31.7 \\
\hline & $\mathrm{BNI}$ & $110.9(12.4)$ & $112.5(22.5)^{\mathrm{A}}$ & $66.3(4.5)^{\mathrm{b}}$ & -40.3 \\
\hline & BI & $112.8(8.2)$ & $109.4(12.0)^{\mathrm{A}}$ & $62.8(25.8)^{\mathrm{b}}$ & -44.4 \\
\hline \multirow{4}{*}{$\begin{array}{l}5000 \text { thermal } \\
\text { cycles }\end{array}$} & CNI-T & $52.1(18.1)^{\mathrm{a}, \mathrm{B}}$ & $104.7(17.5)^{\mathrm{a} \star}$ & $54.0(10.0)^{\mathrm{B}}$ & 3.6 \\
\hline & CI-T & $70.8(15.0)^{\mathrm{ab}, \mathrm{B}}$ & $136.7(27.6)^{b *}$ & $58.3(17.6)$ & -17.6 \\
\hline & BNI-T & $85.0(14.0)^{\mathrm{b}}$ & $146.5(29.1)^{\mathrm{b}, \mathrm{B} *}$ & $56.3(8.5)$ & -33.8 \\
\hline & BI-T & $94.7(18.2)^{\mathrm{b}}$ & $152.8(27.9)^{\mathrm{b}, \mathrm{B} *}$ & $62.5(6.3)$ & -34.0 \\
\hline
\end{tabular}

Within columns, different lowercase letters indicate significant difference within each storage condition and different uppercase letters indicate significant difference between storage conditions. Within rows, ${ }^{*}$ indicates significant difference between $\sigma$ and $\mathrm{PF} \sigma .{ }^{*}$ a negative sign indicates a decrease in the FFL from $\sigma$. Abbreviations: CNI, conventional non-incremental; CI, conventional incremental; BNI, bulk-filled non-incremental; BI, bulk-filled incremental; CNI-T, conventional non-incremental-thermocycled; CI-T, conventional incremental-thermocycled; BNI-T, bulk-filled non-incremental-thermocycled; BI-T, bulk-filled incremental-hermocycled. 


\subsection{Flexural Fatigue Limit (FFL)}

The FFL data (Figure 2) showed that conventional resin composites placed nonincrementally (CNI and CNI-T) had greater fatigue resistance than the bulk-fill resin composites. CNI demonstrated a significantly higher FFL than both BNI and BI $(\mathrm{p}<0.05)$ with the least decrease in strength $(15.9 \%)$ whilst CNI-T was the only group to show an increase in strength (3.6\%) following cyclic fatigue (Table 2). The results indicate that groups with the highest static flexural strength values did not necessarily exhibit greater fatigue resistance.

\subsection{Post-Fatigue Flexural Strength (PF $\sigma)$}

A static four-point bend test on resin composite specimens that survived cyclic fatigue testing was determined to measure the post-fatigue flexural strength (Table 2). There were no statistically significant differences between the composites tested after $24 \mathrm{~h}$ ( $\mathrm{p}>0.05)$, however, following thermocycling, the CNI-T group had significantly lower strength than CI-T and the bulk-filled groups BNI-T and BI-T ( $\mathrm{p}<0.05$ ). Interestingly, the bulk-filled composites BNI and BI showed a significant increase in flexural strength following thermocycling compared to 24 $\mathrm{h}$ storage $(\mathrm{p}<0.05)$. Furthermore, specimens that were subjected to thermocycling showed a significant increase in flexural strength from $\sigma$ to post-fatigue $\sigma$ $(\mathrm{p}<0.05)$, while there was no significant difference for specimens stored for $24 \mathrm{~h}$ $(\mathrm{p}>0.05)$.

\subsection{Fractographic Evaluation}

The fractured surfaces of resin composite specimens subjected to static flexural

120

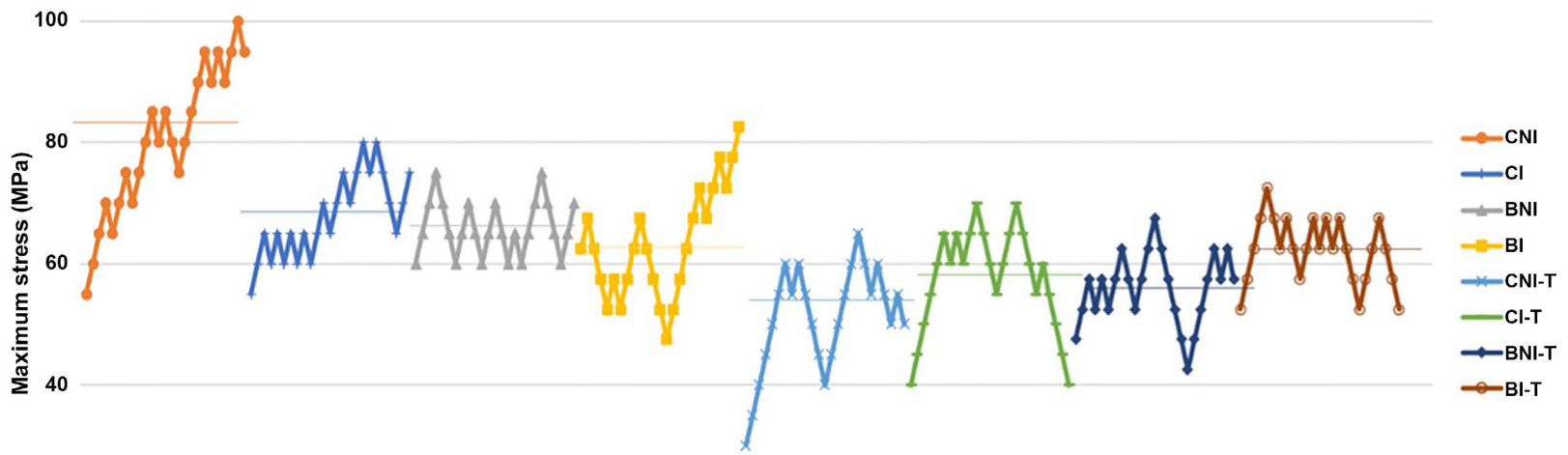

20

Figure 2. FFL of resin composites using the staircase method. Abbreviations: CNI, conventional non-incremental; CI, conventional incremental; BNI, bulk-filled non-incremental; BI, bulk-filled incremental; CNI-T, conventional non-incrementalthermocycled; CI-T, conventional incremental-thermocycled; BNI-T, bulk-filled non-incremental-thermocycled; BI-T, bulkfilled incremental-thermocycled. 
and fatigue tests were evaluated using SEM (Figure 3 and Figure 4). Figure 3(a) and Figure 3(d) show typical fatigue fractured surfaces of the bulk-fill and conventional resin composites, respectively, demonstrating a smooth surface indicating the slower crack growth associated with the viscoelastic creep of the resin matrix characteristic of fatigue failures, whilst Figure 3(b) and Figure 3(e) exhibit typical fractured surfaces of a static fracture in the bulk-fill and conventional resin composites, respectively, showing characteristic features of a rapid fracture indicative of the fast, brittle nature of high-energy static failures. The mist region and hackle lines are visible in Figure 3(c) and Figure 3(f). Fracture origins were frequently located on the tensile surface of the specimen opposite to the point of loading. Higher magnification of the fractured surfaces of the resin composites after cyclic fatigue are shown in Figure 4(a) and Figure 4(b), that demonstrated that propagation of the crack was able to detour around the large pre-polymerised fillers of the bulk-fill resin composite, whilst it resulted in pull-out of the smaller, spherical-shaped filler particles of the conventional resin composite. Under static loads, however, when a crack tip encounters a large filler particle, the absence of a deformable matrix phase results in stress build-up at the crack tip which is transferred to the filler particle, inducing fracture (Figure 4(c), Figure 4(d)). The post-fatigue static failures of thermocycled samples demonstrated in Figure 4(e)
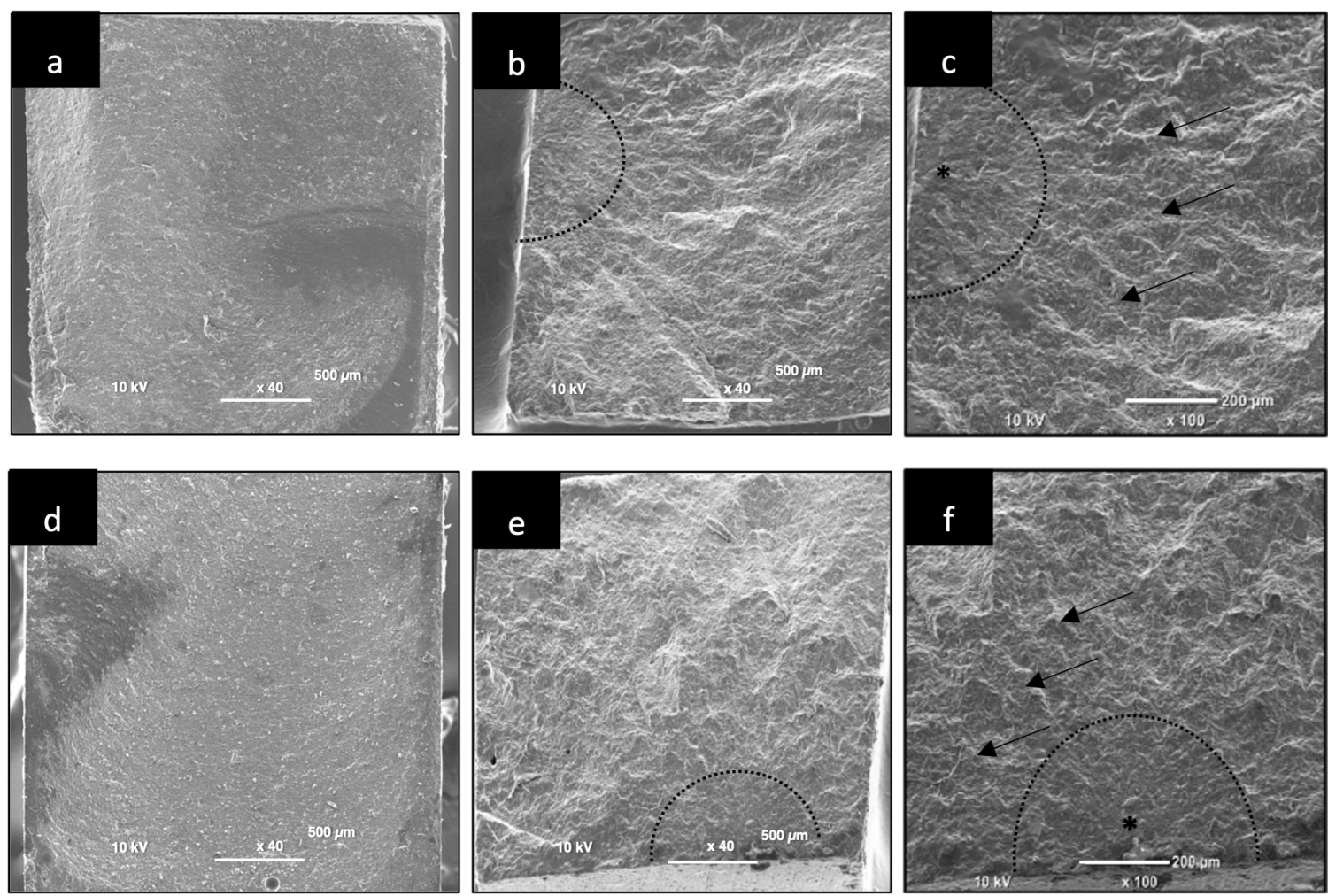

Figure 3. Representative fractured surfaces of the (a-c) bulk-filled and (d-f) conventional resin composites used in this study. Typical fractured surface of $(a, d)$ fatigue fracture with smooth surface; and (b, e) static fracture with macroscopic pattern of a fast fracture. (c, f) show higher magnification of the static factures. Asterisks indicate the fracture origin; dotted lines indicate the mist region; and arrows indicate hackle lines. The origin of the fractures (denoted by the asterisk) is located on the tensile side of the specimen opposite to loading. 

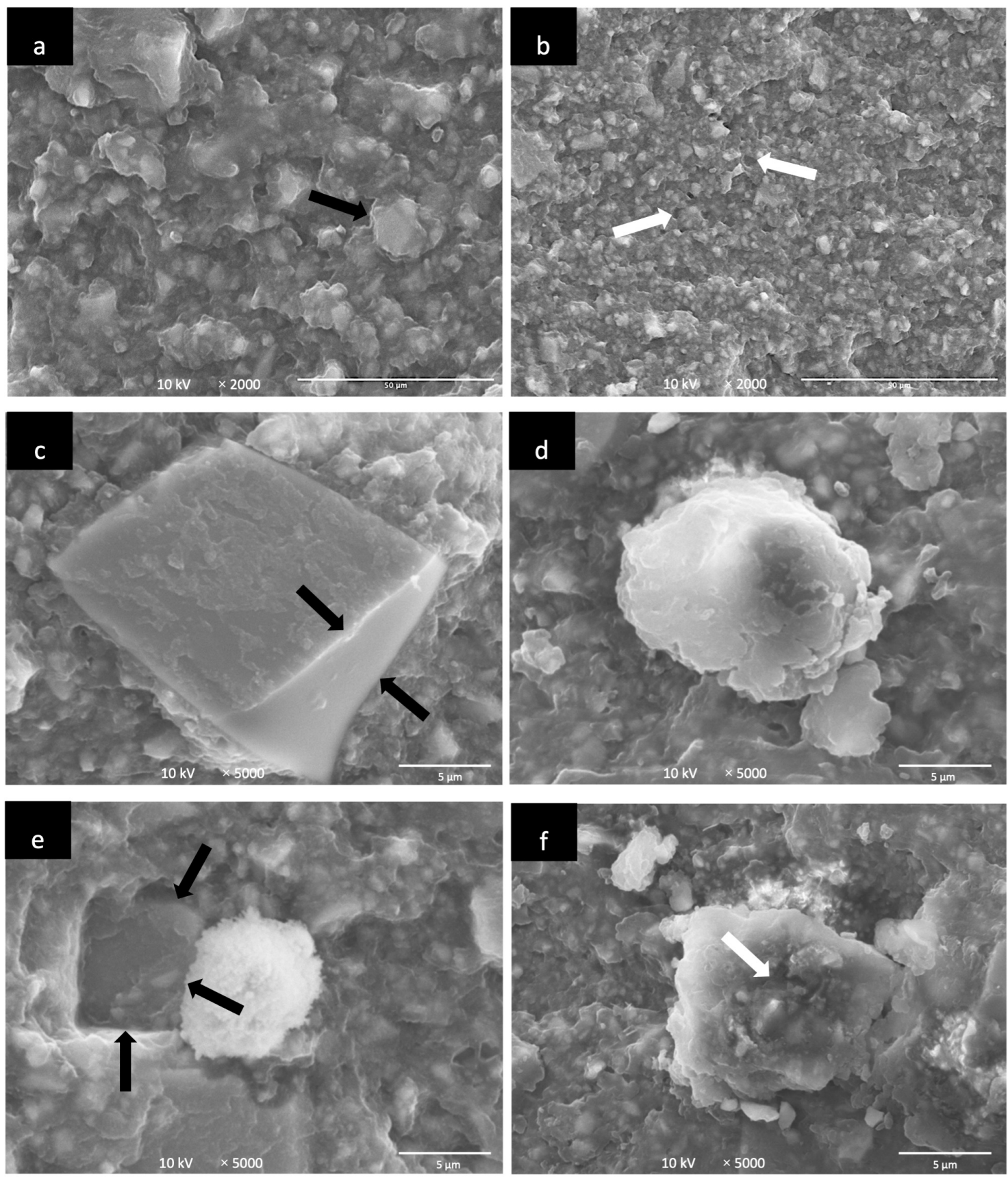

Figure 4. Higher magnification of the (a, c, e) bulk-fill and (b, d, f) conventional resin composites. Following cyclic fatigue, (a) the bulk-fill resin composite demonstrates crack propagation detouring around the larger, pre-polymerised filler particles (black arrow) while (b) the conventional resin composite demonstrates pull-out of the smaller, spherical-shaped filler particles (white arrows). (c) Static failure of the bulk-fill composite show fracture of irregular-shaped pre-polymerised fillers along the crack path (black arrows) while (d) the conventional composite showed preferential crack deflection through the resin matrix without fracture of the smaller, spherical-shaped filler particles. (e) Post-fatigue static failure of thermocycled bulk-fill composite demonstrated detachment of filler particles (black arrows) and (f) post-fatigue static failure of thermocycled conventional composite demonstrated a filler particle not covered by resin (white arrow).

and Figure 4(f) indicated that the interface between the fillers and matrix is the common site of failure, resulting in filler debonding and interfacial resin fracture 
exposing filler particles not covered by resin.

\section{Discussion}

Fatigue is regarded as either a primary or major contributing factor in causing failure of resin composite restorations in the oral environment [15]; however, limited data exists on in vitro fatigue behaviour of the materials [16] [17]. Properties of dental resin composites determined under quasi-static conditions do not necessarily reflect their behaviour under cyclic loads [18], which makes it imperative to understand fatigue behaviour of resin composites, especially if incremental build ups, a commonly used clinical technique to place composites, contributes to fatigue failure as voids between increments can be a confounding factor. The fatigue resistance of the bulk-fill and conventional composites in this study demonstrated that the resin composite with the highest static flexural strength did not necessarily exhibit the highest fatigue resistance. A previous study on resin composites also reported a poor correlation of the fatigue behaviour with static flexural strength values, highlighting flexural fatigue measurements as an important property in evaluating long-term mechanical behaviour of resin composites [19]. Likewise, Belli et al. showed that elastic modulus, flexural strength and fracture toughness had weak correlations with flexural fatigue strength hence were poor predictors of the fatigue resistance of resin composites [20].

Although bulk-filled composites can be cured up to $4 \mathrm{~mm}$ thicknesses, incremental cure was carried out in an identical way for both the bulk-fill and conventional resin composites to ascertain the influence of incremental cure by a single skilled operator. Both type of composites exhibited a similar performance to specimens prepared non-incrementally, hence, the first hypothesis was accepted, as the filling mode of each of the composites had no influence on fatigue behaviour (Table 2). The incremental build-up performed to prepare specimens was used to determine if forming an interface within the composite would affect fatigue, and no effort was made to deliberately create gaps/voids between the increments with the results based on the assumption that there was proper adaptation during specimen fabrication by a single operator. Thus, the in vitro results further indicate that the interface created during incremental build up has low probability of generating voids and imparting porosity in the matrix, enough to adversely affect the fatigue behaviour. McCabe and Ogden compared the compressive fatigue limit of resin composites with and without deliberately introducing air voids and reported that the compressive fatigue resistance was only significantly reduced when the deliberate air voids created porosity within the resin composite [17]. In vitro studies on teeth restored with a bulk-fill resin composite using incremental and non-incremental techniques and compared with those restored with a conventional composite [18], were reported to exhibit a similar fatigue behaviour in keeping with the results of this study. Furthermore, the internal marginal adaptation in restored cavities based on in vitro studies were also not significantly different between placement methods when either 
a bulk-fill or conventional composite was used incrementally or non-incrementally [21]. It is not surprising that voids can cause fatigue life to diminish, affect water uptake and plasticise the matrix. However, this study demonstrated that incremental placement of the conventional and bulk-filled composites had no obvious effect on fatigue, suggesting that incremental layering of composites achieves a good adaptation between the increments and have minimal likelihood of the formation of voids. Hence, fatigue behaviour of the resin composites was more dependent on the type of composite rather than on the incremental cure, a finding that is consistent with a recent meta-analysis indicating that the clinical performance of conventional and bulk-fill resin composites performed similarly when placed in two steps or in bulk [22].

For initial and post-fatigue static flexural strength, bulk-filled composites showed either similar or significantly higher values than conventional composites (Table 2). On the other hand, the conventional composites demonstrated less reduction from initial static flexural strength to flexural fatigue strength (FFL change $=3.6 \%$ to $-31.7 \%$ ) compared to bulk-filled composites (FFL change $=-33.8 \%$ to $-44.4 \%)$. However, it should be noted that assessment of the percentage of change in FFL results from the difference between the mean initial strength and mean residual strength after cyclic loading. As the conventional composites in this study had significantly lower initial strength values than the bulk-filled composites, it is not surprising that the change in FFL is apparently lower in these groups. As both resin composites used in this study had similar filler volume fractions (Table 1), it is likely that the differences in filler particle size and distribution rather than filler content influenced the results. It has been demonstrated that composites with larger filler particle size distribution perform better under faster static loads while those with smaller particle and size distribution exhibit a more favourable performance on cyclic loading due to the predominant viscoelastic behaviour of the resin matrix [19]. Brilliant Everglow is a conventional microfilled composite which when subjected to cyclic loading, allowed cracks to form that propagated through the polymeric matrix resulting in several filler particles being pulled out of the resin matrix (Figure 4(b)). The viscoelastic nature of the resin matrix predominates, and the creep compliance of the resin delays fatigue failure resulting in improved fatigue resistance [19]. However, under high energy static loads, filler particles that are smaller than the plastic zone ahead of the crack tip are more prone to induce crack deflection and resin-filler interface decohesion, hence, the cracks mainly propagated through the matrix and filler/matrix interface (Figure $4(\mathrm{~d})$ ). On the other hand, the bulk-fill resin composite Fill-Up is composed of larger pre-polymerised filler particles around which fatigue-induced cracks were deflected, hence, it provided good mechanical stability under dynamic loading (Figure 4(a)) [20] [23]. When subject to static loads, however, the same effect was not observed. As cracks propagated, the region ahead of the crack tip was predominantly devoid of deformable resin matrix, hence the plastic zone ahead of the crack could not dissipate the generated stress, leading to stress concentration accumulating at the 
crack tip which was high enough to induce particle fracture (Figure 4(c)) [24].

Thermocycling resulted in a significant reduction in the static flexural strength of conventional composites but had no effect on the flexural fatigue behaviour or on bulk-fill composites. Therefore, the second hypothesis was partially rejected. Thermocycling simulates temperature-related breakdown, by causing repeated sudden changes in temperature. However, the impact of thermocycling on the mechanical properties of resin composites is not consistent and seems to be related more to the inherent structure of independent materials. As the bulk-filled composites available in the market vary greatly in terms of resin formulation, filler type and loading, it is difficult to generalise their properties. As a result, some studies have demonstrated no discrepancy in mechanical properties compared to conventional resin composites [25] [26] while others report inferior mechanical properties [27] [28]. Nonetheless, the results presented in this study suggest that the combination of the large filler particle size and greater volume of resin matrix in the bulk-filled composite Fill-Up may have been responsible for its performance under both static and dynamic conditions.

The post-fatigue flexural strength of the specimens determined in this study showed either similar or higher values than the groups that were not subject to pre-cyclic stresses. Since post-fatigue flexural strength was determined on specimens that survived $10^{5}$ cycles which were subjected to cyclic loads well below their static flexural strength (30 - $95 \mathrm{MPa}$; Figure 2), it is likely that it did not have a deteriorating effect on flexural strength values. This can be due to the filler particles in both the resin composites being able to absorb and dissipate any loading stresses that may have developed during cycling, thereby producing a more tolerant system [29]. Previous studies on seven different resin composites have showed similar results on biaxial flexural strengths values where low cyclic loads did not affect post-fatigue strength [30]. In the groups where the specimens were subject to thermocycling, the water uptake would lead to plasticisation of the resin matrix, which can cause blunting at the tip of cracks thereby decreasing stress concentration and may have also generated residual compressive stress at the tips of the cracks thus making the material less brittle and more fracture resistant [20] [30] [31]. These phenomena, either independently or in combination, may have helped prevent concentration of stresses within the resin composite specimens resulting in improved flexural strength. This is demonstrated in Figure 4(e) and Figure 4(f), where post-fatigue failures occurred predominantly at the filler/matrix interface, leading to exposure of filler particles not covered by resin as well as debonding of several filler particles. Hence, postfatigue static fractures favoured crack propagation through the resin matrix, as the lower stress concentration ahead of the crack tip was not sufficient to cause filler fractures compared to initial static fractures.

\section{Conclusions}

The initial flexural strength properties of the resin composites tested seem to be 
associated with microstructural features, whereas the fatigue resistance was more dependent on aspects relating to the matrix phase. The flexural strength and fatigue in flexural mode of the bulk-fill and conventional resin composites showed that the static flexural strength was not correlated with superior fatigue behaviour. Cyclic loading of the two different resin composites clearly indicated that the nature of the composite was more significant, and that incremental build-up of resin composites did not necessarily affect fatigue behaviour due to the presence of an interface. Within the limitations of this experimental study, the results clearly indicate that evaluating fatigue behaviour of restorative materials not adhesively bonded to tooth structure provides valuable information reflecting intra-oral use in stress-bearing areas. This is especially important given that resin composites are current alternatives to amalgam restorations; hence proper selection of resin composite composition for durable application in posterior occlusally-stressed areas is fundamental.

\section{Conflicts of Interest}

The authors declare no conflicts of interest regarding the publication of this paper.

\section{References}

[1] Pallesen, U. and Qvist, V. (2003) Composite Resin Fillings and Inlays. An 11-Year Evaluation. Clinical Oral Investigations, 7, 71-79. https://doi.org/10.1007/s00784-003-0201-Z

[2] Gaengler, P., Hoyer, I. and Montag, R. (2001) Clinical Evaluation of Posterior Composite Restorations: The 10-Year Report. The Journal of Adhesive Dentistry, 3, 185-194.

[3] Hayashi, M. and Wilson, N. (2003) Failure Risk of Posterior Composites with PostOperative Sensitivity. Operative Dentistry, 28, 681-688.

[4] Zhao, X., Li, S., Gu, L. and Li, Y. (2014) Detection of Marginal Leakage of Class V Restorations in Vitro by Micro-Computed Tomography. Operative Dentistry, 39, 174-180. https://doi.org/10.2341/12-182-L

[5] Sultan, A., Moorthy, A. and Fleming, G.J. (2014) The Adhesive Potential of Dentin Bonding Systems Assessed Using Cuspal Deflection Measurements and Cervical Microleakage Scores. Dental Materials, 30, 1154-1160. https://doi.org/10.1016/j.dental.2014.07.005

[6] Ferracane, J.L. (2008) Buonocore Lecture. Placing Dental Composites-A Stressful Experience. Operative Dentistry, 33, 247-257. https://doi.org/10.2341/07-BL2

[7] Soares, C.J., Bicalho, A.A., Tantbirojn, D. and Versluis, A. (2013) Polymerization Shrinkage Stresses in a Premolar Restored with Different Composite Resins and Different Incremental Techniques. The Journal of Adhesive Dentistry, 15, 341-350.

[8] Versluis, A., Douglas, W.H., Cross, M. and Sakaguchi, R.L. (1996) Does an Incremental Filling Technique Reduce Polymerization Shrinkage Stresses? Journal of Dental Research, 75, 871-878. https://doi.org/10.1177/00220345960750030301

[9] Lee, M.R., Cho, B.H., Son, H.H., Um, C.M. and Lee, I.B. (2007) Influence of Cavity Dimension and Restoration Methods on the Cusp Deflection of Premolars in Composite Restoration. Dental Materials, 23, 288-295. 
https://doi.org/10.1016/j.dental.2006.01.025

[10] Abbas, G., Fleming, G.J., Harrington, E., Shortall, A.C. and Burke, F.J. (2003) Cuspal Movement and Microleakage in Premolar Teeth Restored with a Packable Composite Cured in Bulk or in Increments. Journal of Dentistry, 31, 437-444. https://doi.org/10.1016/S0300-5712(02)00121-5

[11] Bicalho, A.A., Pereira, R.D., Zanatta, R.F., Franco, S.D., Tantbirojn, D., Versluis, A. and Soares, C.J. (2014) Incremental Filling Technique and Composite Material-Part I: Cuspal Deformation, Bond Strength, and Physical Properties. Operative Dentistry, 39, E71-E82. https://doi.org/10.2341/12-441-L

[12] Astvaldsdottir, A., Dagerhamn, J., van Dijken, J.W., Naimi-Akbar, A., Sandborgh-Englund, G., Tranaeus, S. and Nilsson, M. (2015) Longevity of Posterior Resin Composite Restorations in Adults-A Systematic Review. Journal of Dentistry, 43, 934-954. https://doi.org/10.1016/j.jdent.2015.05.001

[13] Baran, G., Boberick, K. and McCool, J. (2001) Fatigue of Restorative Materials. Critical Reviews in Oral Biology \& Medicine, 12, 350-360.

https://doi.org/10.1177/10454411010120040501

[14] Draughn, R.A. (1979) Compressive Fatigue Limits of Composite Restorative Materials. Journal of Dental Research, 58, 1093-1096. https://doi.org/10.1177/00220345790580031101

[15] Kruzic, J.J., Arsecularatne, J.A., Tanaka, C.B., Hoffman, M.J. and Cesar, P.F. (2018) Recent Advances in Understanding the Fatigue and Wear Behavior of Dental Composites and Ceramics. Journal of the Mechanical Behavior of Biomedical Materials, $\mathbf{8 8}$, 504-533. https://doi.org/10.1016/j.jmbbm.2018.08.008

[16] Arola, D. (2017) Fatigue Testing of Biomaterials and Their Interfaces. Dental Materials, 33, 367-381. https://doi.org/10.1016/j.dental.2017.01.012

[17] McCabe, J.F. and Ogden, A.R. (1987) The Relationship between Porosity, Compressive Fatigue Limit and Wear in Composite Resin Restorative Materials. Dental Materials, 3, 9-12. https://doi.org/10.1016/S0109-5641(87)80053-2

[18] Rauber, G.B., Bernardon, J.K., Vieira, L.C., Maia, H.P., Horn, F. and Roesler, C.R. (2016) In Vitro Fatigue Resistance of Teeth Restored With Bulk Fill versus Conventional Composite Resin. Brazilian Dental Journal, 27, 452-457.

https://doi.org/10.1590/0103-6440201600836

[19] Ornaghi, B.P., Meier, M.M., Lohbauer, U. and Braga, R.R. (2014) Fracture Toughness and Cyclic Fatigue Resistance of Resin Composites with Different Filler Size Distributions. Dental Materials, 30, 742-751.

https://doi.org/10.1016/j.dental.2014.04.004

[20] Takeshige, F., Kawakami, Y., Hayashi, M. and Ebisu, S. (2007) Fatigue Behavior of Resin Composites in Aqueous Environments. Dental Materials, 23, 893-899.

https://doi.org/10.1016/j.dental.2006.06.031

[21] Furness, A., Tadros, M.Y., Looney, S.W. and Rueggeberg, F.A. (2014) Effect of Bulk/Incremental Fill on Internal Gap Formation of Bulk-Fill Composites. Journal of Dentistry, 42, 439-449. https://doi.org/10.1016/j.jdent.2014.01.005

[22] Arbildo-Vega, H.I., Lapinska, B., Panda, S., Lamas-Lara, C., Khan, A.S. and Lukomska-Szymanska, M. (2020) Clinical Effectiveness of Bulk-Fill and Conventional Resin Composite Restorations: Systematic Review and Meta-Analysis. Polymers, 12, 1786. https://doi.org/10.3390/polym12081786

[23] Drummond, J.L., Lin, L., Al-Turki, L.A. and Hurley, R.K. (2009) Fatigue Behaviour of Dental Composite Materials. Journal of Dentistry, 37, 321-330.

https://doi.org/10.1016/j.jdent.2008.12.008 
[24] Belli, R., Petschelt, A. and Lohbauer, U. (2014) Are Linear Elastic Material Properties Relevant Predictors of the Cyclic Fatigue Resistance of Dental Resin Composites? Dental Materials, 30, 381-391. https://doi.org/10.1016/j.dental.2014.01.009

[25] Ilie, N., Bucuta, S. and Draenert, M. (2013) Bulk-Fill Resin-Based Composites: An in Vitro Assessment of Their Mechanical Performance. Operative Dentistry, 38, 618-625. https://doi.org/10.2341/12-395-L

[26] Vidhawan, S.A., Yap, A.U., Ornaghi, B.P., Banas, A., Banas, K., Neo, J.C., Pfeifer, C.S. and Rosa, V. (2015) Fatigue Stipulation of Bulk-Fill Composites: An in Vitro Appraisal. Dental Materials, 31, 1068-1074.

https://doi.org/10.1016/j.dental.2015.06.006

[27] Leprince, J.G., Palin, W.M., Vanacker, J., Sabbagh, J., Devaux, J. and Leloup, G. (2014) Physico-Mechanical Characteristics of Commercially Available Bulk-Fill Composites. Journal of Dentistry, 42, 993-1000.

https://doi.org/10.1016/j.jdent.2014.05.009

[28] Goracci, C., Cadenaro, M., Fontanive, L., Giangrosso, G., Juloski, J., Vichi, A. and Ferrari, M. (2014) Polymerization Efficiency and Flexural Strength of Low-Stress Restorative Composites. Dental Materials, 30, 688-694.

https://doi.org/10.1016/j.dental.2014.03.006

[29] Curtis, A.R., Palin, W.M., Fleming, G.J., Shortall, A.C. and Marquis, P.M. (2009) The Mechanical Properties of Nanofilled Resin-Based Composites: Characterizing Discrete Filler Particles and Agglomerates Using a Micromanipulation Technique. Dental Materials, 25, 180-187. https://doi.org/10.1016/j.dental.2008.05.013

[30] Curtis, A.R., Palin, W.M., Fleming, G.J., Shortall, A.C. and Marquis, P.M. (2009) The Mechanical Properties of Nanofilled Resin-Based Composites: The Impact of Dry and Wet Cyclic Pre-Loading on Bi-Axial Flexure Strength. Dental Materials, 25, 188-197. https://doi.org/10.1016/j.dental.2008.06.003

[31] Lin, L. and Drummond, J.L. (2010) Cyclic Loading of Notched Dental Composite Specimens. Dental Materials, 26, 207-214.

https://doi.org/10.1016/j.dental.2009.10.002 